\title{
Formação profissional de curta duração em um minicurso de montagem de computador no Instituto Federal do Pará, Ilha do Marajó
}

Short-term professional training in a computer assembly mini-course at the Federal Institute of Pará, Marajó Island

Formación profesional de corto plazo en minicurso de montaje de computadora en el Instituto Federal de Pará, Isla do Marajó

\section{Resumo}

Este trabalho tem como finalidade demostrar a importância de montagem de computadores através de minicurso, uma alternativa prática e eficiente para a construção de conceitos de informática, para avaliar qual a relevância que o curso tem para a formação, qualificação e perspectiva de trabalho para os participantes. Foi comparado dois públicos-alvo diferenciado, o primeiro, alunos da Instituição Federal de Ensino, e o segundo, membros da sociedade externa A 'I Escola de Férias, realizada pelo Instituto Federal de Educação, Ciência e Tecnologia do Pará - Campus Breves, com o objetivo de aplicação de métodos alternativos de ensino prático. Assim, foi realizado entre os dias 03 a 07 de julho de 2017, com participação de 21 alunos, sendo eles servidores, alunos do Curso Técnico em Informática Integrado ao Ensino Médio com duração de 20 horas, o Minicurso - Montagem de Computadores. Neste sentido, é necessário fazer uma análise do processo de ensino e aprendizagem desenvolvido no minicurso, assim como as perspectivas de impacto deste minicurso para a formação do participante para o mercado de trabalho, levando em consideração o atual momento histórico da tecnologia da informação que vivemos. Este trabalho apresenta os resultados obtidos a partir da avaliação do minicurso, realizada através da aplicação de um questionário.

Palavras-chave: Formação; Perspectiva; Trabalho; Ensino; Aprendizagem; Informática.

\begin{abstract}
This paper aims to demonstrate the importance of computer assembly through mini-course, a practical and efficient alternative for the construction of computer concepts, to evaluate the relevance of the course for the training, qualification and work perspective for the participants. Two different target audiences were compared: the first, students of the Federal Educational Institution, and the second, members of the external society A 'I School of Vacations, held by the Federal Institute of Education, Science and Technology of Pará - Campus Breves, with the objective of applying alternative methods of practical teaching. Thus, it was held from 03 to 07 July 2017, with the participation of 21 students, being servants, students of the Technical Course in Integrated Computer Science to High School with duration of 20 hours, the Mini-Course - Computer Assembly. In this sense, it is necessary to make an analysis of the teaching and learning process developed in the mini-course, as well as the perspectives of the impact of this mini-course for the training of the participant for the labor market, taking into account the current historical
\end{abstract}


moment of information technology that we live. This paper presents the results obtained from the evaluation of the mini-course, carried out through the application of a questionnaire

Keywords: Training; Perspective; Job; Teaching; Learning; Computing.

\begin{abstract}
Resumen
Este trabajo tiene como objetivo demostrar la importancia de ensamblar computadoras a través de un curso corto, una alternativa práctica y eficiente para la construcción de conceptos informáticos, para evaluar la relevancia que tiene el curso para la formación, capacitación y perspectiva laboral de los participantes. Se compararon dos públicos destinatarios diferentes, el primero, estudiantes de la Institución Educativa Federal, y el segundo, miembros de la sociedad externa A 'I Escola de Férias, realizada por el Instituto Federal de Educación, Ciencia y Tecnología de Pará Campus Breves, con el objetivo de aplicar métodos alternativos de enseñanza práctica. Así, se llevó a cabo entre el 3 y el 7 de julio de 2017, con la participación de 21 alumnos, siendo servidores, alumnos del Curso Técnico en Informática Integrada a Bachillerato con una duración de 20 horas, el Minicurso - Ensamblaje de Computadoras. En este sentido, es necesario hacer un análisis del proceso de enseñanza y aprendizaje desarrollado en el mini-curso, así como las perspectivas de impacto de este mini-curso para la formación del participante para el mercado laboral, teniendo en cuenta las momento histórico actual de las tecnologías de la información que vivimos. Este trabajo presenta los resultados obtenidos de la evaluación del curso corto, realizada mediante la aplicación de un cuestionario. Palabras clave: Capacitación; Perspectiva; Trabajo; Ensenãnza; Aprendiendo; Informática.
\end{abstract}

\title{
1. Introdução
}

A formação da sociedade moderna é majoritariamente organizada nos moldes do sistema capitalista de produção que ao longo do espaço e do tempo vem construindo e formando a sociedade conforme o desenvolvimento da técnica aplicada em cada fase da história da humanidade. É importante destacar que apesar da formação e constituição da sociedade através das técnicas de produção pertencerem ao sistema capitalista essa formação e constituição não garante formações de espaços homogêneos de técnicas de produção, tão pouco é capaz de solucionar definitivamente os problemas de caráter social.

Conforme Santos (2001, p.11): "as técnicas são oferecidas como um sistema e realizada combinadamente através do trabalho e das formas de escolhas dos momentos e dos lugares de seu uso". É a "precariedade do emprego e da remuneração; a e regulamentação das condições de trabalho em relação às normas legais vigentes ou acordadas e a consequente regressão dos direitos sociais, [...] configurando uma tendência à individualização extrema da relação salarial” (Bihr Apud Antunes, 2000, p.52).

A formação e constituição do espaço através do meio técnico de produção capitalista passaram por alterações significativas ao longo da história, deste os períodos da revolução industrial até os dias atuais, com a chamada revolução global que ainda está em processo de formação. As evidências históricas de formação dos meios de produção social através das técnicas justificam o atual momento que constitui fase de produção. Segundo Santos (2001, p.12): "O desenvolvimento da história vai de par com o desenvolvimento das técnicas".

A técnica da informação constitui o atual período da história da humanidade através da eletrônica, cibernética, da informática. Através de sistemas computacionais constituídos de hardware (componentes físicos) e softwares (componentes softwares) que fazem parte do cotidiano das pessoas descrevendo o modo de vida, intervindo no comportamento, na saúde, na educação e nas atividades profissionais das sociedades contemporâneas, transformando-as conforme seus interesses e necessidades.

Outro fator importante deste momento histórico é a formação da chamada sociedade digital que habitam e navegam nas redes de computadores. Essa formação da sociedade digital através das redes de computadores chamada Internet, tem dinâmica e formação heterogenias de organização no espaço e no tempo, ou seja, são criadas comunidades dinâmicas que se utilizam da instantaneidade da informação para se articularem conforme determinadas atividades fins.

A integração entre educação, tecnologia e sociedade é uma questão emergente. Com a presença, cada vez mais constante, da tecnologia no dia-a-dia das pessoas torna-se impossível desconsiderá-la. Segundo Benakouche (1998, p. 2), este afirma que "se existe um consenso a respeito das principais características das sociedades contemporâneas, este se refere à 
presença cada vez maior da tecnologia da organização das práticas sociais”. De fato, a sociedade contemporânea assiste a uma transformação das estruturas institucionais mergulhadas numa crise de legitimidade e um dos desafios do mundo globalizado concentra-se em compreender e construir modelos tecnológicos que permitam uma reestruturação constante da sociedade, compatível com uma possível diminuição das diferenças sociais existentes. Nesse sentido, ao pensarmos a educação como espaço de sociabilização faz-se necessário discutir formas de utilização, de tecnologias no mundo das instituições escolares (Lang, 2007).

Dentro deste contexto, a inclusão de atividades práticas e cursos extracurriculares no decorrer da formação podem ser estratégias que propiciem melhor desenvolvimento profissional e formação de um perfil multiprofissional (Gondin, 2002; Pereira et al., 2011). Essa relação entre aprendizagem e trabalho, se constituem através das aulas teóricas e práticas, na qual o aluno tem a oportunidade de aplicar o conteúdo visto em sala de aula na prática, com o objetivo de consolidar a aprendizagem. Para Minarelli (1995), os profissionais precisam estar aptos do ponto de vista técnico, gerencial, intelectual, humano e social para solucionar com rapidez problemas cada vez mais sofisticados e específicos e, além disso, o mercado valoriza dá preferência a profissionais com múltiplas habilidades e com iniciativa. Desta forma, percebe-se a necessidade de desenvolver habilidades de todos os aspectos durante a formação do profissional. De acordo com Moreira et al., (2020), o mercado de trabalho está cada vez mais exigente e por conta disso as pessoas procuram-no e se dedicam para obter uma qualificação de qualidade para poder atuar em suas áreas de trabalho.

Considerando a deficiência da formação profissional e as lacunas deixadas pela formação destes profissionais, o objetivo deste trabalho foi verificar se é possível promover formação profissional e habilitar profissionais para atuarem na área profissional do minicurso de montagem de computador de curta duração. O objetivo específico do trabalho foi analisar cada grupo distinto através do questionário, relacionando-os entre o processo de formação aprendizagem e o processo de formação profissional, considerando a importância da interversão do minicurso para cada um destes grupos no processo de formação profissional e no processo de aprendizagem para atuarem na atividade de montagem de computadores.

\section{Metodologia}

\subsection{O local da pesquisa}

O estudo foi realizado no Instituto Federal do Pará - Campus Breves, no qual está localizado no Arquipélago do Marajó (Figura 1), tendo na sua área de abrangência os municípios de Afuá, Anajás, Bagre, Breves, Chaves, Curralinho, Gurupá, Melgaço e Portel, tendo como missão a educação profissional e tecnológica, através do ensino, pesquisa e extensão, articulando os saberes e a diversidade sociocultural, técnico-informacional para formação de cidadãos comprometidos com o desenvolvimento sustentável marajoara. Situa-se a margem esquerda do Rio Parauaú, distante $160 \mathrm{~km}$ em linha reta de Belém, tendo como principal forma de acesso o transporte fluvial, com duração média de 6h (lancha) ou 12h (navio/balsa) de viagem para a capital do Estado, Belém, e por via aérea em até 45 minutos de duração.

Atualmente o Campus Breves possui a oferta dos seguintes cursos: na modalidade de subsequente tem-se: Técnico em Informática para a Internet, Técnico em Meio Ambiente, Técnico em Edificações, Técnico em Saneamento e Técnico em Agropecuária; na modalidade integrado ao ensino médio, o Curso Técnico em Informática; e os cursos na modalidade de formação continuada: Operador de Computador, Montador e reparador de Computadores, Agricultor Familiar, Criador de Peixes em Viveiros Escavados.

Esta proposta teve por base a realização de um evento de integração e aproximação entre a comunidade acadêmica do Campus e a sociedade local: 'I Escola de Férias do IFPA - Campus Breves. 
Figura 1. Mapa representando a localização do IFPA Campus Breves no Município de Breves, PA.

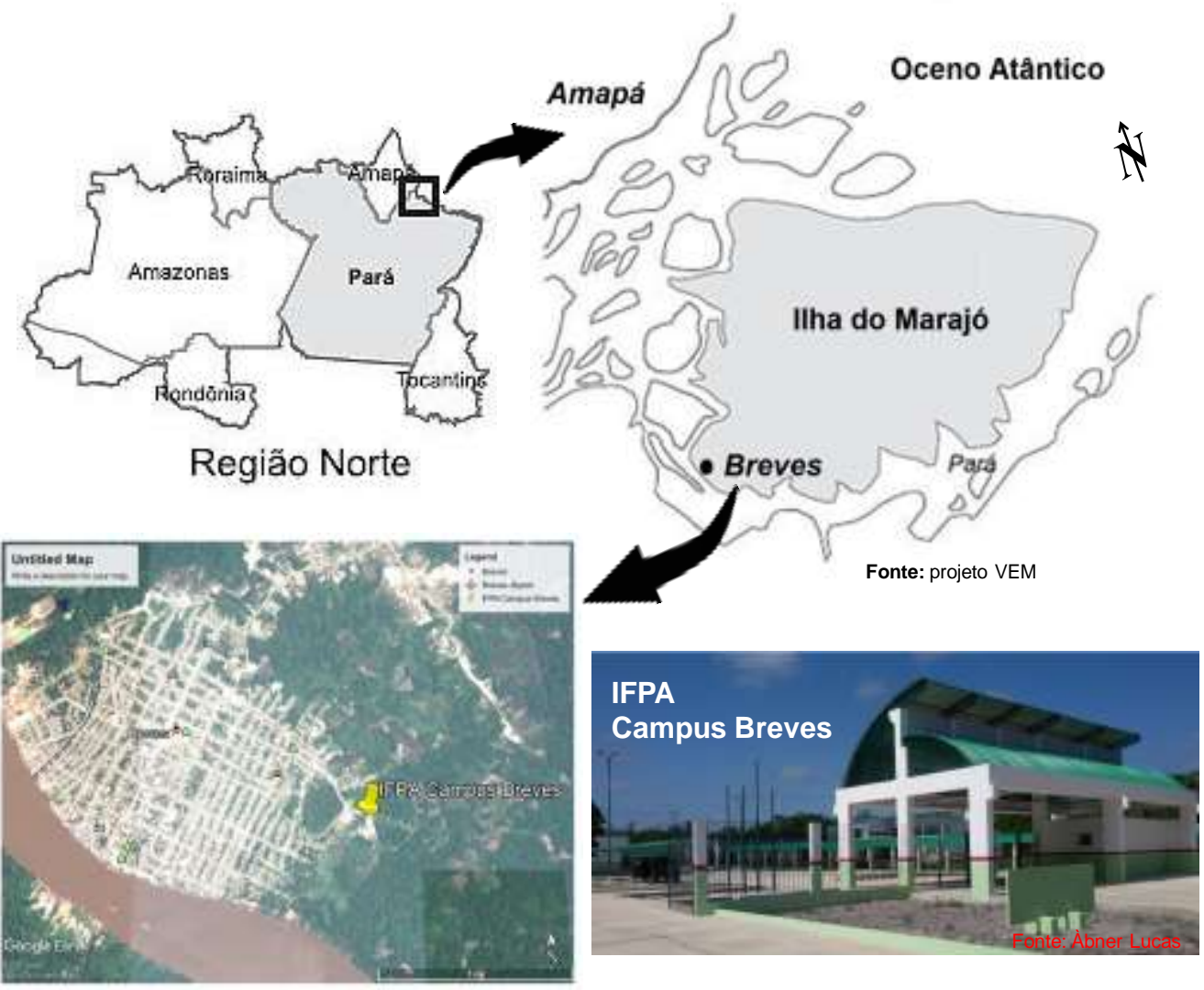

Fonte: Adaptado de Google Earth (2019).

\subsection{Tipo de pesquisa realizada}

A metodologia adotada para analisar o desenvolvimento da disciplina e os desafios encontrados foi o estudo de caso. A vantagem do estudo de caso é a sua aplicabilidade a situações humanas, a contextos contemporâneos de vida real com a possibilidade de observar e acompanhar em profundidade o desenrolar dos acontecimentos (Dooley, 2002). O autor refere ainda que:

Investigadores de várias disciplinas usam o método de investigação do estudo de caso para desenvolver teoria, para produzir nova teoria, para contestar ou desafiar teoria, para explicar uma situação, para estabelecer uma base de aplicação de soluções para situações, para explorar, ou para descrever um objeto ou fenómeno (Dooley, 2002, p. 343344).

Segundo Gamboa (1997), nessa abordagem qualitativa, o foco da pesquisa é colocado na "experiência individual de situações" para compor o "processo de construção de significados". Trata-se de um tipo de pesquisa que é, a um só tempo, descritiva e explicativa quanto aos seus objetivos comuns, pois propicia estudar a descrição das características dos sujeitos envolvidos, bem como suas opiniões e concepções sobre o objeto da investigação (Gil, 2002). Dessa forma, o trabalho possui natureza quali-quantitativa, conforme Koche (2012), sendo que a pesquisa qualitativa busca interpretar dados da realidade a partir da perspectiva dos pesquisados, mediante a máxima valorização do contato direto com a situação estudada, (Gil, 1999). Enquanto a quantitativa implica na utilização de medidas previamente estabelecidas, cujos resultados sejam quantificáveis, garantindo o estabelecimento de conclusões seguras e confiáveis (Gil, 1999). 
Apesar de não haver rigidez no roteiro para a realização de estudos de caso, Gil (2002) assinala que podem ser identificadas quatro fases: (a) delimitação da unidade-caso; (b) coleta de dados; (c) seleção, análise e interpretação dos dados (d) elaboração de um relatório.

\subsection{Forma de aplicação da pesquisa e públicos-alvo}

No IFPA Campus Breves foi realizado um evento de integração e aproximação entre a comunidade acadêmica do Campus e a sociedade local: 'I Escola de Férias do IFPA - Campus Breves. Neste evento, buscou-se através de minicursos e oficinas de curta duração, ofertar uma educação complementar aos alunos dos cursos do IFPA e membros da comunidade externa com o objetivo de ampliar seus conhecimentos no período das férias escolares. Tais atividades foram ofertadas em quaisquer níveis de escolaridade desde que tivessem interesse nos minicursos/oficinas oferecidos. As inscrições foram gratuitas, realizadas de forma online e presencial, com certificação entregue a todos que participarem do evento, desde que cumprida à frequência mínima exigida. Desta forma, esta semana acadêmica caracterizou-se por ser uma atividade de extensão oportuna na promoção e capacitação de recursos humanos em assuntos pertinentes à realidade marajoara, seja no contexto econômico, social, ambiental, político e/ou cultural.

A Escola de Férias foi realizada no período de 03 à 07 de julho de 2017 nas instalações do Instituto Federal de Educação, Ciência e Tecnologia do Estado do Pará - Campus Breves. Dentre os minicursos ofertados havia o minicurso de "Montagem de Computadores", tendo como objetivo desenvolver atividades teóricas e prática voltada para montagem de computadores, possibilitando aos participantes obterem conhecimentos também de manutenção de computadores, com uma carga horária de 20 horas.

O minicurso proporcionou aos participantes, aulas teóricas objetivando apresentar teorias fundamentadas sobre computadores e aulas práticas, momento em que os participantes tiveram contato com os computadores aliado a teoria e prática, possibilitando consolidar o processo de ensino e aprendizagem do conteúdo ministrado, levando em consideração que as atividades práticas permitem a fixação do conteúdo teórico e facilita no processo de aprendizagem do conteúdo ministrado. É importante destacar que a proposta do minicurso, foi trabalhar aspecto teórico-prático, destaque para a prática, levando em consideração que atividade prática reforça a teoria. Portando, o aluno assistiu o processo físico de desmontagem e montagem de um computador, assim como assistiu o processo de instalação dos softwares que compõem um sistema computacional.

Desta forma, o conteúdo teórico foi abordado no mesmo momento em que foi executado a prática de montagem de computador. O aluno estuda o sistema computacional de um computador desktop, os periféricos, a parte física da máquina (hardware), os componentes software do computador. Os alunos desenvolveram atividades de montagem e instalaram os softwares (sistema operacional e aplicativo) da máquina, sendo assim, os alunos puderam observar e manipular as máquinas, conhecendo-os suas características e funções.

Os materiais didáticos utilizados no minicurso foram: 10 computadores tipo desktop completos contendo monitor, mouse e teclado, 10 kits de ferramentas, 10 mídias de DVD e CD contendo sistema operacional e 3 mídias contendo programas de instalação.

Ao final do processo, os participantes organizaram-se em grupos, para receber novamente instruções e acompanhamento para executarem todas as etapas do processo desmontagem e montagem do computador com segurança, além de instalarem os softwares necessários que compõem o sistema computacional. A partir do momento em as equipes sentiramse seguras para executarem suas tarefas, os alunos estavam aptos para desenvolverem as atividades de montagem, desmontagem e instalação do sistema de software de forma autônoma.

Ao finalizar o minicurso, o participante adquire a habilidade em montagem e desmontagem de computador, conhece as características as funcionalidades de periféricos, instalar sistema operacional e aplicativos. 
Para se obter os resultados da pesquisa, o público-alvo do minicurso de montagem de computador contou com um total de 21 inscritos, sendo público alunos interno e externo do IFPA Campus Breves, conforme destacado no (Gráfico 1).

Gráfico 1. Público-alvo inscrito no minicurso montador de computador oferecido no IFPA Campus Breves durante a I Escola de Férias.

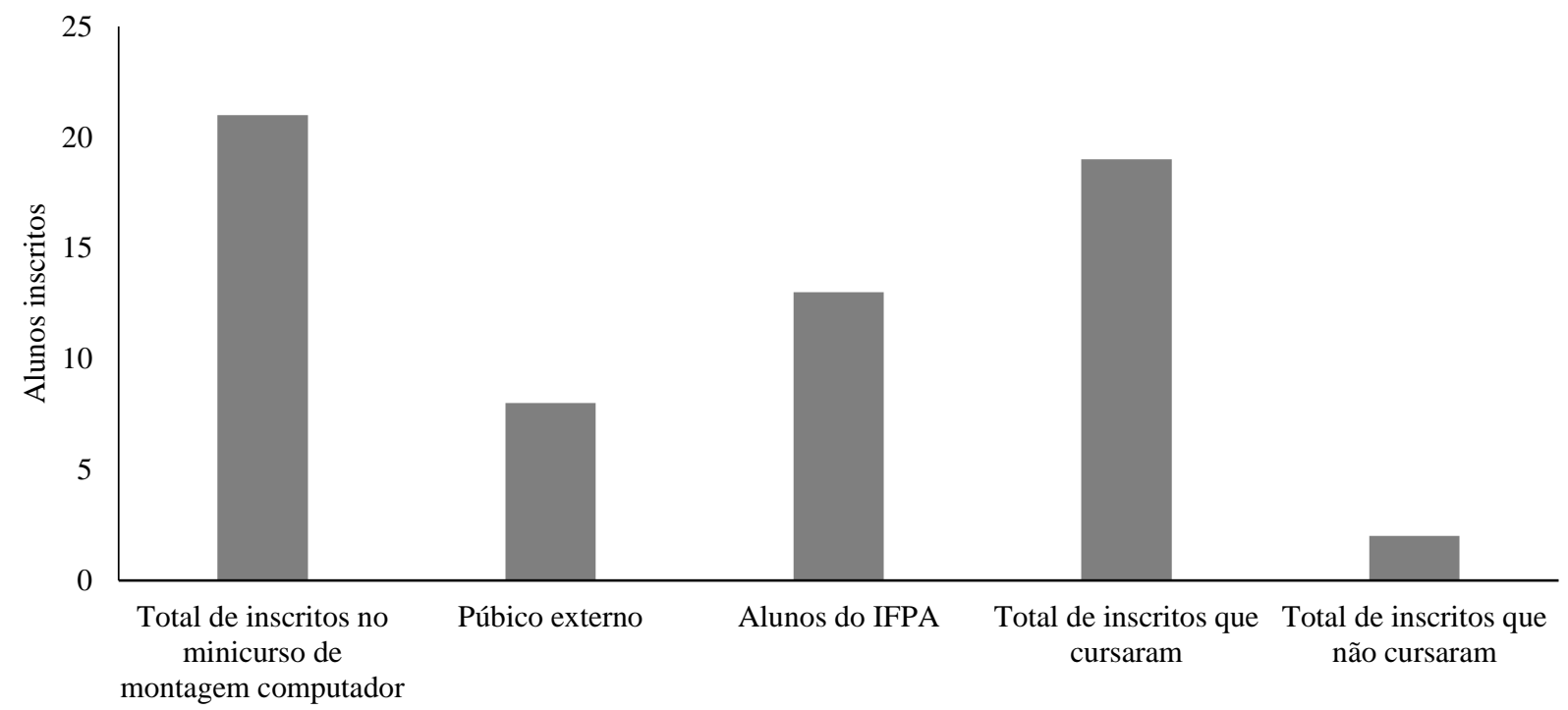

Fonte: Dados da pesquisa.

\subsection{Métodos de análises de resultados}

A avaliação do minicurso surgiu devido à necessidade de relatar a percepção dos participantes (alunos), referente (sobre) as contribuições do minicurso de montador de computadores nas atividades de formação e produção de técnica. Para o processo de análise dos resultados foi elaborado um questionário estruturado, contendo 10 questões, dessas, 2 questões objetivas e 8 subjetiva que continha algumas questões relacionadas à análise dos alunos quanto à contribuição do minicurso e a associação teoria e prática, para analisar a expectativa dos participantes do minicurso em relação as atividades e as perspectivas após concluírem o curso

Estes questionários foram aplicados presencialmente com cópias impressas apresentadas aos públicos-alvo, que por sua vez preencheram à caneta e devolveram para análise. Dessa forma, os questionários contribuem para melhor descrição e compreensão da realidade, sobre o que foi observado durante a realização do minicurso e como os alunos absorveram o conhecimento proporcionado. Segundo Lakatos e Marconi (2009, p. 201) o questionário é "um instrumento de coleta de dados, construído por uma série ordenada de perguntas, que devem ser respondidas por escrito e sem a presença do entrevistador". Para Gil (1999, p. 128-129), “a vantagem do questionário, é que o aluno pode pensar em suas respostas e enviá-las ao seu tempo, não envolvendo custos, e assim, terem maior liberdade para responder as perguntas".

Os dados coletados foram tratados mediante uma análise quali-quantitativa, tabulados no programa Excel 2013, no qual foram obtidos gráficos, sendo analisados e discutidos, posteriormente, com base em literatura pertinente, procurando evidenciar os resultados e obter conhecimentos sobre a opinião dos alunos entrevistados a respeito da problemática supracitada. Assim, foi possível, separar dois grupos distintos fundamentais para análise dos resultados, o primeiro grupo contém os alunos da Instituição de Ensino - IFPA, o segundo grupo é formado membros da comunidade externa. 


\section{Resultados e Discussão}

Os eventos realizados pelas Instituições vêm se consolidando como um importante espaço de dinamização de discussões e avanços de ensino de uma determinada especialidade, promovendo a integração do desenvolvimento cultural, científico e profissional não somente da comunidade acadêmica, mas também da sociedade. Para desenvolver a análise dos resultados obtidos, foi necessário discriminar os participantes envolvidos na pesquisa classificando-os em dois grupos distintos, a saber, grupos dos alunos regularmente matriculados no IFPA - Campus Breves denominados aqui de comunidade interna e os grupos dos inscritos nos minicursos que não são matriculados regularmente na instituição de ensino, denominados de comunidade externa.

Neste sentido, o minicurso contou com o número de 21 inscritos, deste total, 19 (dezenove) inscritos participaram das aulas, e destes, 18 (dezoito) participantes responderam ao questionário perfazendo uma amostragem de aproximadamente 95\%, conforme apresentado no (Gráfico 2).

Gráfico 2. Público que respondeu o questionário aplicado ao fim do minicurso montador de computador oferecido no IFPA Campus Breves durante a I Escola de Férias.

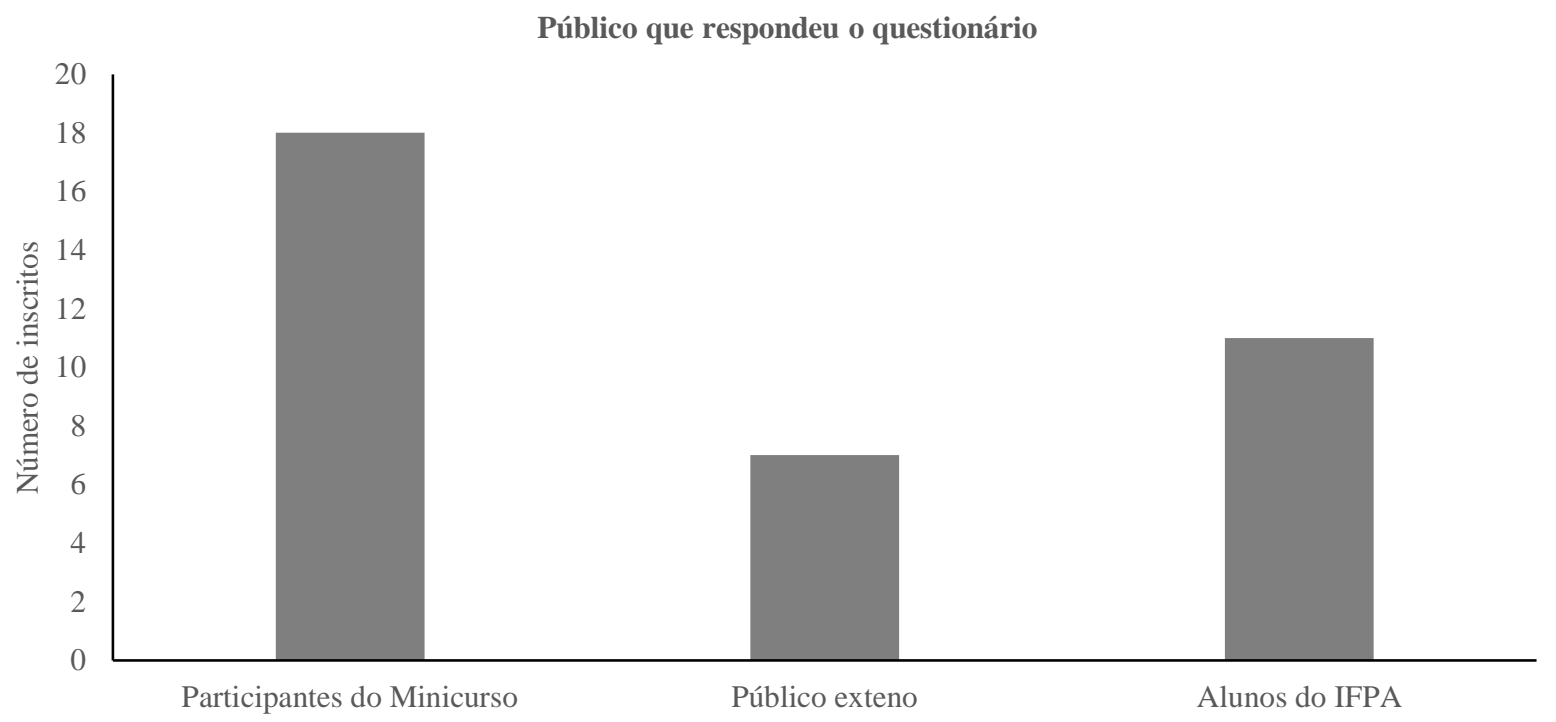

Fonte: Dados da pesquisa.

De acordo com o Gráfico 2, responderam ao questionário, 18 (dezoito) participantes, destes, 11 (onze) são alunos do IFPA - Campus Breves, com percentual de 61,11\% dos participantes e 7 são membros da comunidade externa, representando o percentual 38,89\% dos participantes, conforme mostra a Tabela 1. Esses dados, refletem o alto índice dos participantes no feedback aos questionários aplicados, assegurando e demonstrando um alto nível de confiabilidade em relação aos resultados obtidos na pesquisa realizada. Destaca-se assim, a importância de ser ter essas atividades estabelecendo uma relação entre instituição e sociedade. Essa aproximação acontece por meio de troca de conhecimentos e experiências entre professores, alunos e a comunidade externa, pela possibilidade de desenvolvimento de processos de ensino-aprendizagem, a partir de práticas, juntamente com o ensino, propiciando o confronto da teoria com o mundo real de necessidade e desejos (Hennington, 2005). 
Tabela 1 - Total de inscritos, participantes e que responderam ao questionário do minicurso montador de computador oferecido no IFPA Campus Breves durante a I Escola de Férias.

\begin{tabular}{c|c|c|c}
\hline & \multicolumn{2}{|c|}{ Inscritos } & Participantes da entrevista \\
\hline Públicos-alvo & Total & Participantes & Total \\
\hline Alunos do IFPA & 14 & 12 & 07 \\
\hline Comunidade externa & 07 & 07 & 18 \\
\hline TOTAL & 21 & 19 & 11 \\
\hline
\end{tabular}

Fonte: Dados da pesquisa.

É válido ressaltar a presença e participação hegemônica dos alunos da comunidade interna do IFPA no minicurso em relação à comunidade externa. Esta hegemonia deve-se a contribuição de dois fatores determinantes: o primeiro, a divulgação das inscrições do minicurso, ocorridas nas salas de aula possibilitando aos alunos da instituição de ensino, encaminharem-se de forma coletiva para o local das inscrições; e o segundo motivo, a facilidade do acesso às inscrições aos alunos do IFPA. Destaca-se aqui, que as inscrições foram ofertadas em duas modalidades, presencial, no IFPA Campus Breves através da web, via e-mail. Nesse sentido, a popularidade das redes sociais foi uma grande estratégia utilizada na divulgação do referido evento. Entretanto, apesar da importância da divulgação na realização de eventos, o sucesso deste não se encontra relacionado apenas à divulgação, mas, também a outros aspectos, como o interesse e motivação do público-alvo. Segundo Paz et al., (2014) é um dos principais problemas mais discutido no cenário nacional, quando abordamos a realidade do sistema educacional brasileiro e a motivação dos alunos.

No Gráfico 4, é possível observar que os alunos do IFPA foram identificados e discriminados de acordo com o curso, em que cada um deles estão matriculados na instituição. Nota-se presença de alunos inscritos no minicurso de outras áreas do conhecimento, que à primeira vista, não fazem relação direta com a área da informática, dentre elas então as áreas do curso técnico em agropecuária e do curso técnico em saneamento. Essa informação é relevante na medida em que instiga a questionamentos reflexivos e um deles é sobre qual é a finalidade da formação do minicurso para estes inscritos.

No entanto, já era esperado o número expressivo de alunos da área de informática, inscritos no minicurso, consolidando assim, o esperado. Apesar da maioria dos alunos pertencerem a área de informática, a presença do público de outras áreas de conhecimento no minicurso, pode ser considerado um indício que indica a importância da diversificação de conhecimentos nos dias atuais no processo de formação, assim como, pode pontar para a necessidade de incluir no currículo, outras atividades profissionais. Nota-se pelo Gráfico 4, que é notório que nos dias de hoje, o computador é usado para ensinar qualquer assunto não apenas computação, mas é usado como objetivo de estudos, onde o aluno por meio da informática adquire conceitos teóricos e práticos, conforme afirma Souza (2010). Para Lacerda (2012, p.4) "diante tanta modernidade tecnológica, vemos a necessidade de inserir a informática no contexto educacional em diversas disciplinas a fim de construir conhecimentos para o uso das diversas ferramentas e linguagens no contexto escolar e também no dia a dia", o que justifica a busca do minicurso por diferentes cursos técnicos da Instituição. 
Gráfico 4. Público dos alunos da Instituição de acordo com o Curso que estão matriculados que participaram do minicurso montador de computador oferecido no IFPA Campus Breves durante a I Escola de Férias.

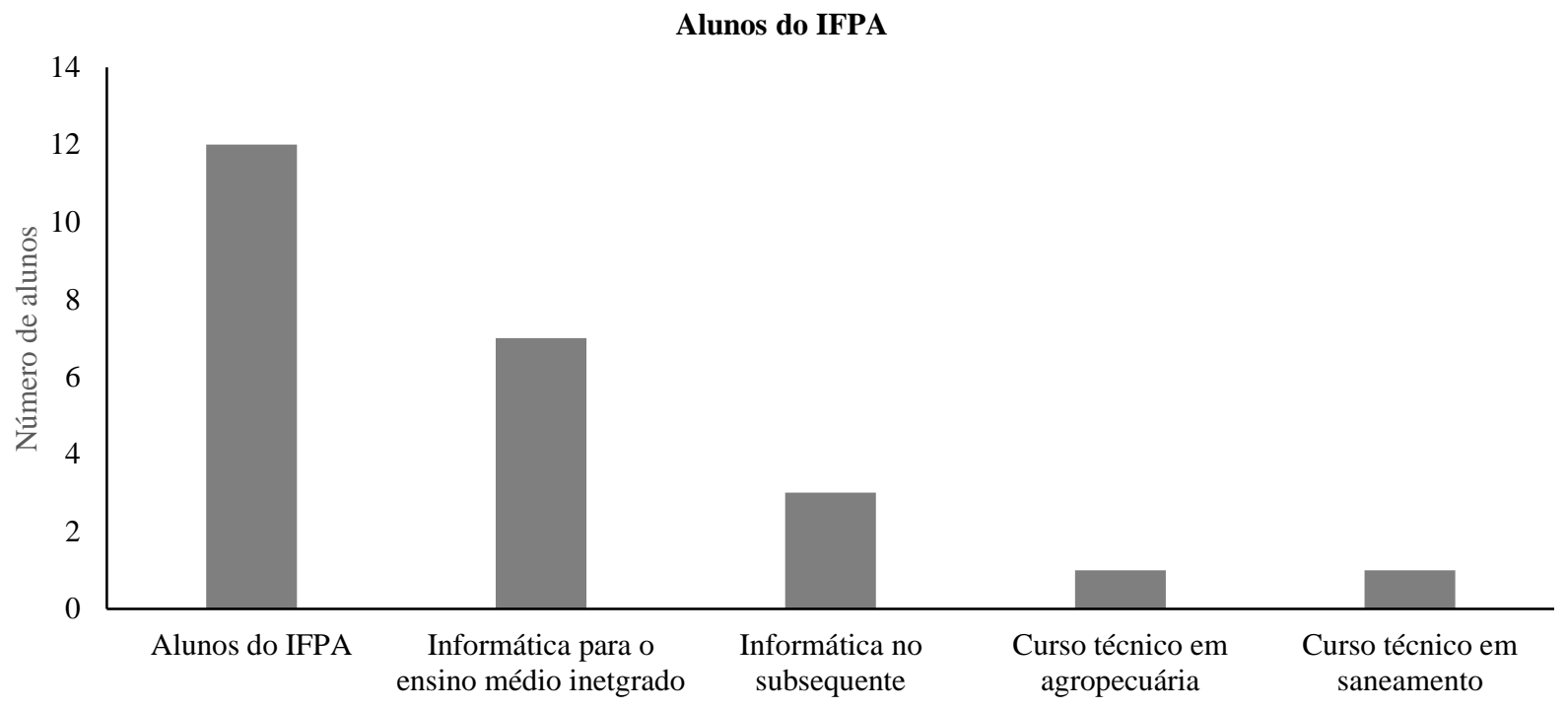

Fonte: Dados da pesquisa.

De acordo com o Gráfico 5, é possível observar, para uma posterior análise, o grau de escolaridade dos participantes da comunidade externa. Observou-se que dos 7 (sete) inscritos que fazem parte do público externo, 4 (quatro) estão inseridos na formação superior, cerca de $57,15 \%$ dos inscritos e 3 (três) inscritos, cerca de $42,85 \%$ não estão inseridos na formação superior, também não informaram se possuem outra formação profissionalizante. Nessa perspectiva, observa-se dos inscritos que possuem formação superior, o interesse em diversificarem na área de conhecimento, mesmo que essa formação não tenha o mesmo grau da formação superior, visando obter outra alternativa de atividade profissional.

Gráfico 5. Grau de escolaridade dos participantes da comunidade externa que participaram do minicurso montador de computador oferecido no IFPA Campus Breves durante a I Escola de Férias.

\section{Participantes externos}

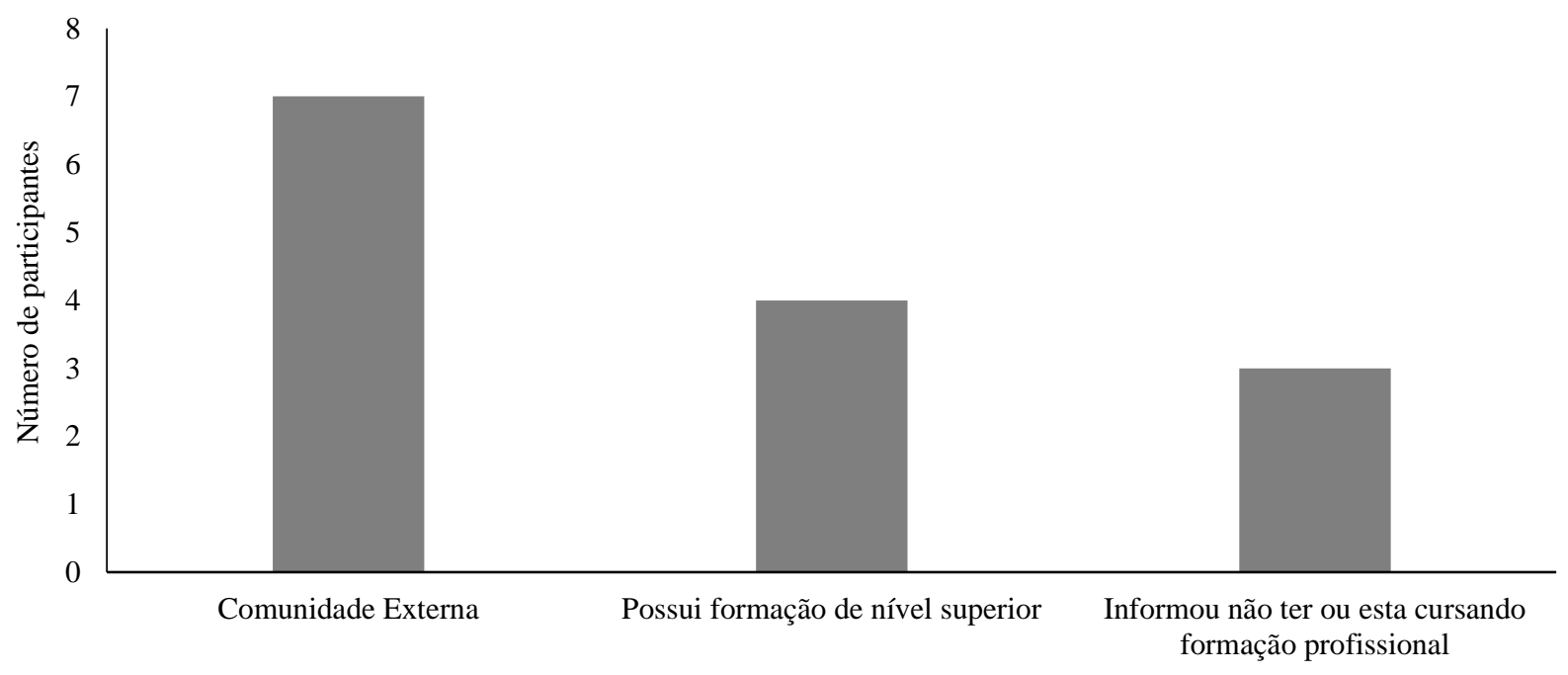

Fonte: Dados da pesquisa.

O Gráfico 6, refere-se as respostas obtidas da primeira questão, que instiga a quantidade dos inscritos, que trabalham ou pretendem trabalhar na atividade de montagem de computadores, 15 (quinze) dos inscritos responderam que sim e 3 (três) 
responderam que não trabalham ou não pretendem trabalhar na atividade. Estes dados apontam para o percentual de $83,33 \%$ dos entrevistados, a pretensão de continuarem exercendo a atividade no ramo de montagem de computador e $16,67 \%$ responderam que não pretendem trabalhar ou continuar exercendo com atividades no ramo.

Gráfico 6. Questionário sobre se pretendem trabalhar do minicurso montador de computador oferecido no IFPA Campus Breves durante a I Escola de Férias.

Você trabalha ou pretende trabalhar com atividade de montagem de computadores?

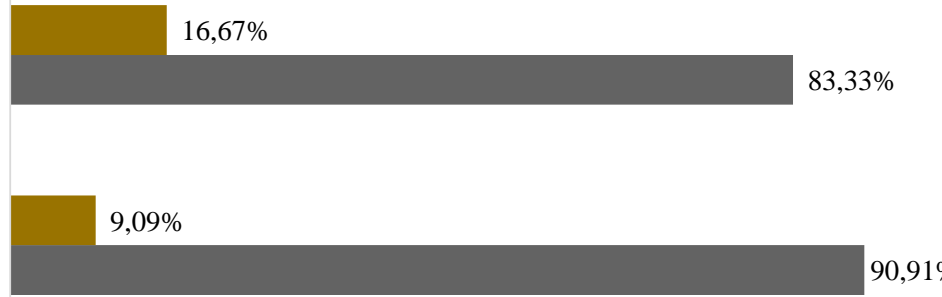

Número dos participantes da Instituição de ensino

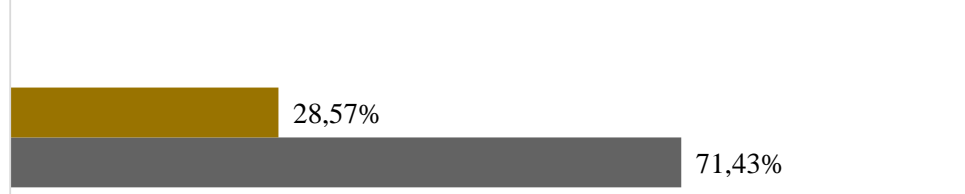

Número dos participantes da comunidade

$$
\text { - Não } \square \text { Sim }
$$

Fonte: Dados da pesquisa.

Em relação aos 11(onze) inscritos que fazem parte do público interno da Instituição de Ensino - IFPA que responderam ao questionário, 10 (dez) responderam que pretendem continuar no ramo da montagem de computador e 1 (um) apenas respondeu que não trabalha e não pretende trabalhar com atividade de montagem de computadores. Isso significa que 90,91\% responderam sim e 9,09\% responderam não.

Dos 7 (sete) participantes da comunidade externa que responderam ao questionário, 5 (cinco) responderam sim, pretendem trabalhar com atividade de montador e 2 (dois) responderam não, o que correspondem a 71,43\% de sim e $28,57 \%$ não. Os resultados dos dados apresentados na Figura 6 revelam a importância do minicurso para o processo de formação profissional dos participantes do minicurso.

Quando a pergunta foi sobre o que os levou a participarem do minicurso, do total de 15 (quinze) respostas, 5 (cinco) responderam melhor compreensão do assunto, 4(quatro) responderam curiosidade, 4(quatro) responderam afinidade com a área e 2 (dois) responderam qualificação para o mercado de trabalho, conforme Gráfico 7. Este fato demonstra que os estudantes estão cada vez mais envolvidos nestas atividades, devido principalmente, à necessidade de aquisição de novas experiências que complementem o currículo, definição profissional e a urgência em vivenciar aprendizados significativos (Peres et al., 2007).

Os resultados do Gráfico 7, mostram que 5 (cinco) participantes se inscreveram no minicurso para compreender melhor o assunto que é abordado no minicurso, cerca de 33,33\% dos entrevistados, 4(quatro) responderam que a curiosidade pelo curso foi o motivo que os levaram a participarem, cerca de 26,67\% dos entrevistados, para outros 4 (quatro), a afinidade com a área foi o motivo cerca de $26,67 \%$ e 2 (dois) justificaram a qualificação para o mercado de trabalho como motivo de estarem cursando o minicurso, ou seja, cerca de $13,33 \%$. 
Gráfico 7. Questionário sobre o que os levou a participaram do minicurso montador de computador oferecido no IFPA Campus Breves durante a I Escola de Férias.

Os participantes da comunidade externa responderam

Os participantes da Instituição de Ensino responderam

Qual o motivo que o levou a escolher o curso de montador de computador?

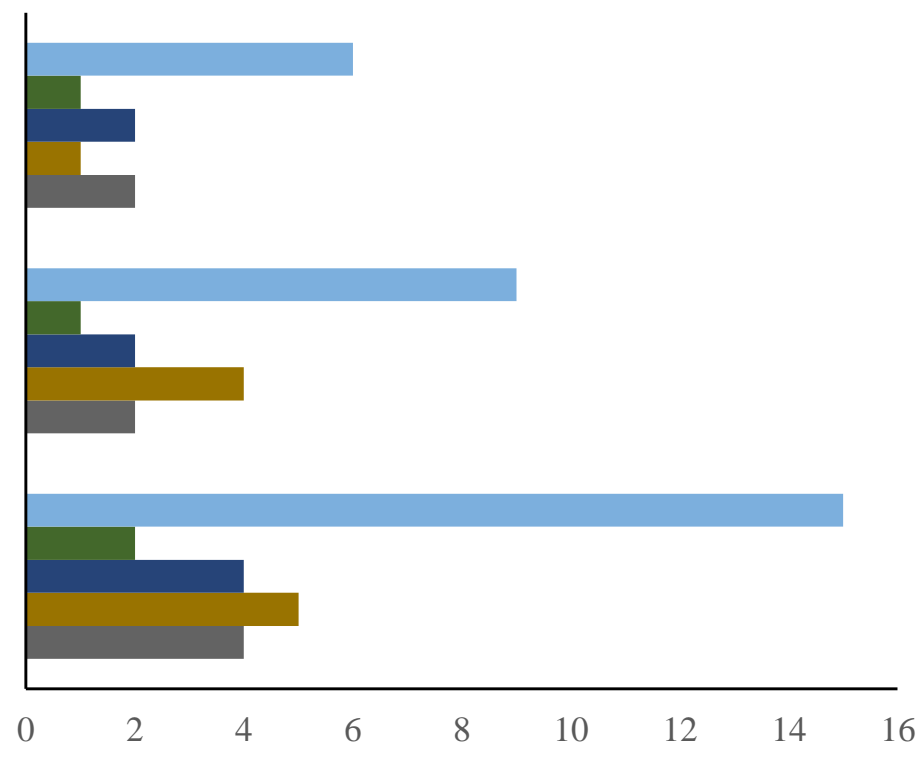

- Total Qualificação mercado de trabalho

Fonte: Dados da pesquisa.

Dessa forma, os resultados mostram que apenas $13,33 \%$ dos inscritos no curso, objetivaram a qualificação para o mercado de trabalho na área e 33,33\% justificaram suas inscrições para compreender melhor o minicurso. Inicialmente esse resultado pode demonstrar que o motivo das inscrições não foi à necessidade de ingressar no mercado de trabalho, mas, o interesse em conhecer melhor o curso para depois tomar a decisão. Analisando a questão, 86,67\% estavam aguardando o curso iniciar para tomar a decisão, esse percentual de 13,33\%, são as pessoas que já sabiam do que o curso iria abordar. Quando questionados, sobre a relação de afinidade do participante em relação às atividades de montagem de computadores, os participantes tiveram que escolher uma das 4 (quatro) opções de múltiplas escolhas.

As opções distribuídas em muita importância, importante, pouca importância e nenhuma importância, pretendeu-se mesurar o grau de afinidade os participantes tiveram em relação as atividades de montagem de computadores, dos 18 (dezoito) participantes que responderam essa questão, 9 (nove) marcaram muito importante, 8 (oito) marcaram importante e 1 (um) marcou pouca importância, totalizando 100\%, conforme Gráfico 8.

No Gráfico 8 , um total de 50\%, consideraram que mantiveram uma relação de afinidade muito importante com atividades de montagem de computador exercida no minicurso, 44,44\% consideram essa relação importante e 5,56\% consideram pouca importância essa relação de afinidade. Analisando os $50 \%$ que consideram ter uma afinidade muito importante, 77,78\% são alunos são do IFPA e 22,22\% são da comunidade externa. Já os 44,44\% que consideram essa relação importante, $50 \%$ são da comunidade externa, 50\% são alunos do IFPA. Somando os resultados dos alunos do IFPA que consideram muito importante ou importante, o percentual é de $61,11 \%$ e a soma do percentual da comunidade externa é de $38,89 \%$. Esse resultado indica que os alunos do IFPA apresentam um perfil de afinidade para o minicurso maior comparado com a comunidade externa. 
Gráfico 8. Questionário sobre a relação com as atividades de montagem de computadores no minicurso de montador de computador oferecido no IFPA Campus Breves durante a I Escola de Férias.

Os participantes da comunidade externa responderam

Os participantes da Instituição de Ensino responderam

Qual a sua relação com a atividades de montagem de computador?

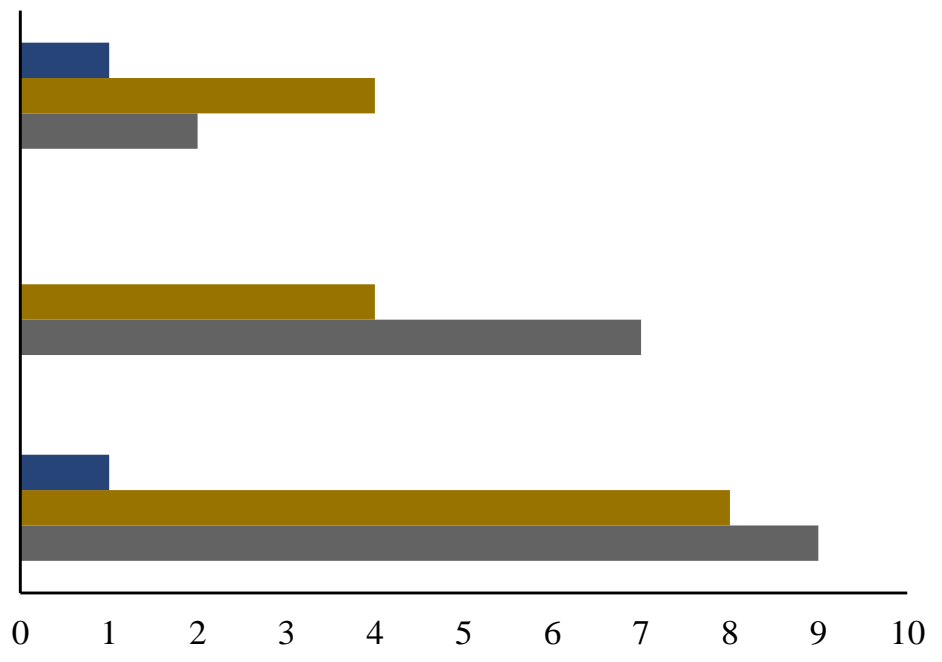

घenhuma importância $\quad$ • Pouca importância $\quad$ Importante $\quad$ Muita importância

Fonte: Dados da pesquisa.

Esse perfil pode ser justificado através de outra analise a ser feita pela quantidade de alunos de informática que estão inscritos no curso em relação aos não estudantes. O número de estudantes de informática inscritos no minicurso é de 9 alunos, os não cursam informática são 9. Existe uma relação de 50\% dos inscritos pertencerem ao curso de informática e os outros $50 \%$ dos inscritos, não pertencerem ao curso de informática. Dos 50\% inscritos no minicurso, $100 \%$ são alunos do curso de informática, 77,78\% consideram ter uma afinidade muito importante e 22,22\% consideram ter uma afinidade importante. Em relação aos inscritos que não fazem parte do curso de informática, 22,22\% consideram ter uma afinidade muito importante, 66,67\% consideram ter uma afinidade importante e 11,11\% consideram pouca importância essa relação de afinidade com o minicurso. O resultado reafirma que os alunos de informática de uma relação de afinidade maior com atividade de montagem de computador em relação aos não alunos, podendo ser um indicativo que expressa que as atividades exercidas nos cursos podem definir o perfil profissional do aluno.

Em relação a quarta questão, quando questionados sobre a importância do curso de montador para a formação profissional, obteve-se as seguintes respostas: Um grupo de 9 (nove) pessoas responderam que o curso proporcionou uma melhor compreensão sobre as atividades exercidas por um profissional da área, 5 (cinco) consideraram importante a qualificação e 2 (dois) destacaram a versatilidade da formação como fator relevante, conforme Gráfico 9.

Considerando que 52,94\% responderam que o minicurso os ajudou a compreenderem sobre as atividades exercidas por um profissional na área da montagem de computador, esse percentual indica que o minicurso pode ser um elemento importante para aqueles que estão indecisos em escolher a carreira profissional para seguir. Essa análise é importante, na medida em que muitos jovens podem ter a oportunidade de escolher antes de acessar uma educação profissional ou superior a área de conhecimentos que lhe é mais oportuno. Neste sentido, o minicurso pode ser utilizado como um instrumento inovador e avaliativo fundamental no processo seletivo para direcionar os candidatos para determinados cursos. 
Gráfico 9. Questionário sobre a importância do minicurso de montagem de computador oferecido no IFPA Campus Breves durante a I Escola de Férias.

Os participantes da comunidade externa responderam

Os participantes da Instituição de Ensino
responderam

Por que o curso de montador de computador foi importante para sua formação profissional?

घotal $\quad$ Versatilidade da formação

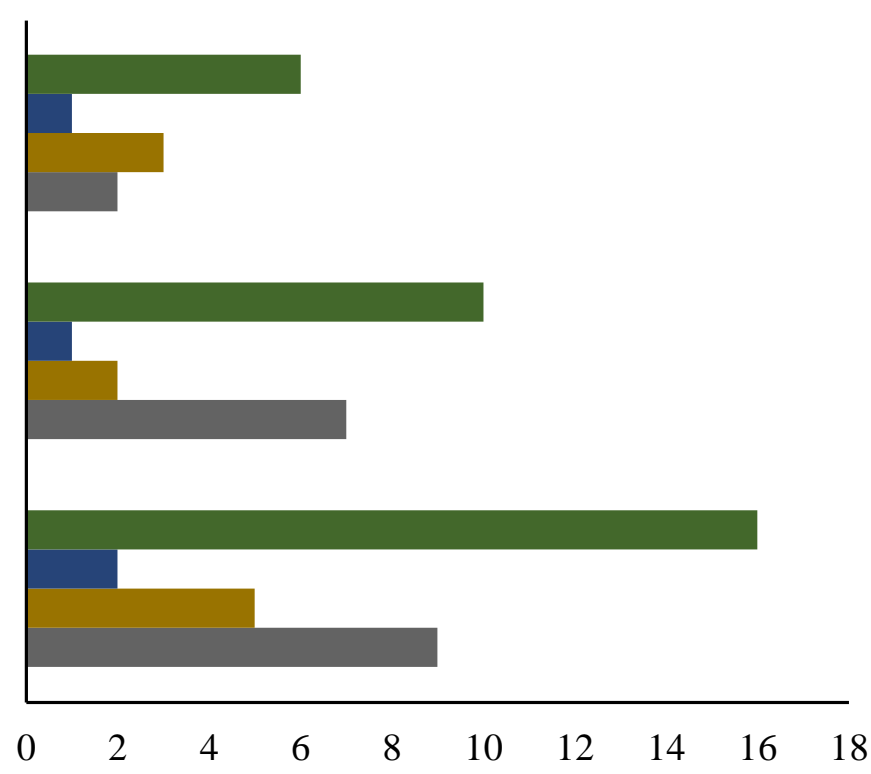

घualificação $\quad$ — Melhor compreensão do assunto

Fonte: Dados da pesquisa.

Quando questionados sobre a dificuldade encontrada no desenvolvimento das atividades realizadas do curso, 4 (quatro) responderam que tiveram dificuldades a instalação do painel frontal com a placa mãe, 5 (cinco) responderam a instalação do sistema operacional e 5 (cinco) responderam que não tiveram dificuldades, Gráfico 10.

Em relação às dificuldades encontradas no minicurso das 14 (quatorze) respostas, 28,58\%, identificaram a instalação do painel frontal com a placa mãe, 35,71\% responderam instalação do sistema operacional e 35,71\% responderam que não tiveram dificuldades. As dificuldades mencionadas são tratadas como indicadores importantes do processo de ensino e aprendizagem, levando em consideração que o processo de avaliação é contínuo.

Essa etapa do questionário pode ser tratada como etapa de diagnóstico do processo avaliativo, como tal, esse processo obteve sucesso, na medida em que foram identificadas as dificuldades no processo de ensino e aprendizagem. Levando em consideração o percentual de 64,29\% das respostas sinalizando insucessos no processo de aprendizagem, foi possível identificar e sugerir em outro momento oportuno alterações que facilitem a melhor compreensão do conteúdo.

Segundo Lukesi:

O resgate do significado diagnóstico da avaliação, que aqui propomos como um encaminhamento para ultrapassagem do autoritarismo, de forma alguma quer significar menos rigor na prática da avaliação. Ao contrário, para se diagnóstica, a avaliação deverá ter o máximo possível de rigor no seu encaminhamento. Pois o rigor técnico e científico no exercício da avaliação garantirão ao professor, no caso, um instrumento mais objetivo de tomada de decisão (Lukesi, 2005, p.44). 
Gráfico 10. Questionário sobre a dificuldade encontrada nas atividades no minicurso de montador de computador oferecido no IFPA Campus Breves durante a I Escola de Férias.

Os participantes da comunidade externa responderam

Os participantes da Instituição de Ensino responderam

Qual foi sua dificuldade no curso de montagem de computador?

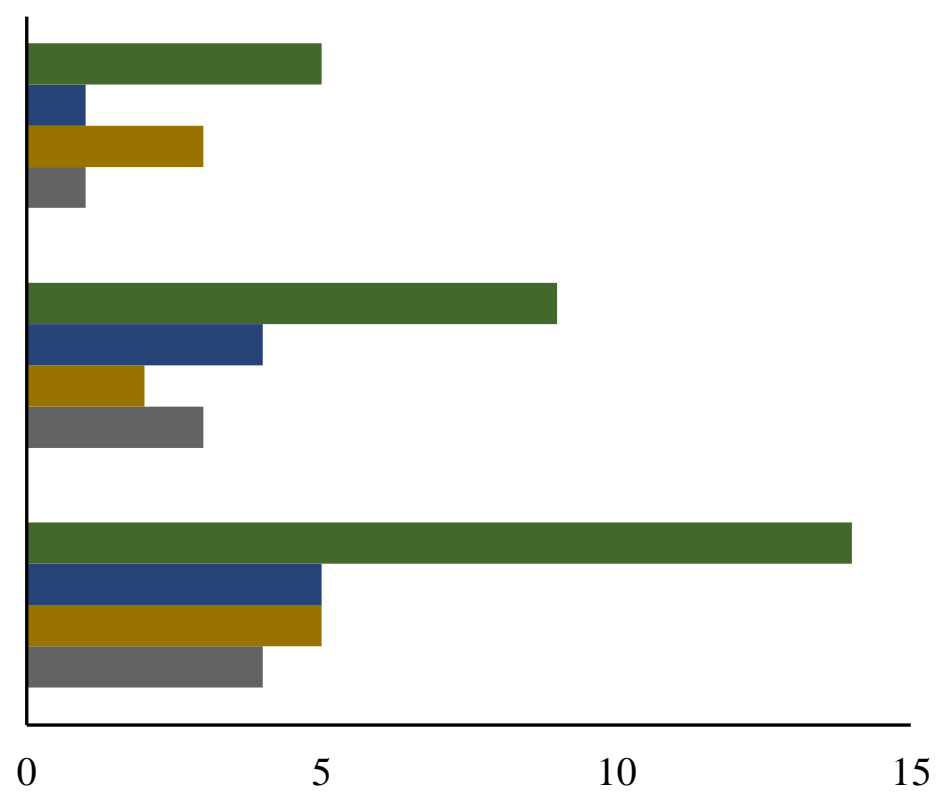

- Total Nenhuma Instalaçao do sistema operacional $\square$ Instalaçao dos componentes do painel frontal

Fonte: Dados da pesquisa.

Outra questão de múltipla escolha, do questionário foi em qual das etapas os participantes tiveram maior facilidade em aprender. Dentre eles, 16 (dezesseis) participantes responderam, sendo10 (dez) marcaram montagem de computador e 6 (seis) marcaram instalação de sistema operacional. Do total de 16 participantes, 9 (nove) são alunos do IFP, e desses, 6 (seis) responderam montagem e 3 (três) responderam instalação do sistema operacional. Do total de 16 (dezesseis), 7 (sete) são da comunidade externa, e desses, 4 (quatro) responderam montagem e 3 (três) responderam instalação do sistema operacional, conforme Gráfico 11.

De acordo com o Gráfico 11, estabelecendo uma comparação entre os dois grupos, 66,67\% dos alunos do IFPA e 57,14\% da comunidade externa responderam que tiveram facilidade em aprender o processo de montagem do computador. Para 33,33\% dos alunos da Instituição e $42,86 \%$ da comunidade externa, responderam que tiveram maior facilidade em aprender instalação de sistema. Comparando os percentuais das respostas obtidas entre os dois públicos a atividade de montagem de computador foi a que o público compreendeu com mais facilidade. Essa facilidade da aprendizagem pode estar associada a atividade prática de montagem desenvolvida durante o curso, momento em que os participantes do minicurso manipularam os componentes físicos do computador, desenvolvendo atividades de desmontagem e montagem do computador. Nesse sentido, a relação teoria-prática possibilita que o aluno esteja presente em situações problematizadoras e assim construa, pela prática, de um saber experimental (Winterhalter; Nogueira, 2012).

Sobre a atividade de instalação do sistema operacional por se tratar de uma atividade que além da prática, requer um nível de abstração maior em relação a montagem, a percentagem foi menor. Neste sentido, o percentual apresentado, reforça que as atividades de cunho prático e físico tem melhor chance de ser bem-sucedida no processo de ensino e aprendizagem se comprado com processo que exigem um pouco mais de abstração para execução. 
Gráfico 11. Questionário sobre a etapa que tiveram maior facilidade em aprender no minicurso de montador de computador oferecido no IFPA Campus Breves durante a I Escola de Férias.

Os participantes da comunidade externa responderam

Os participantes da Instituição de Ensino responderam

Qual a etapa você teve maior facilidade de aprendizagem?

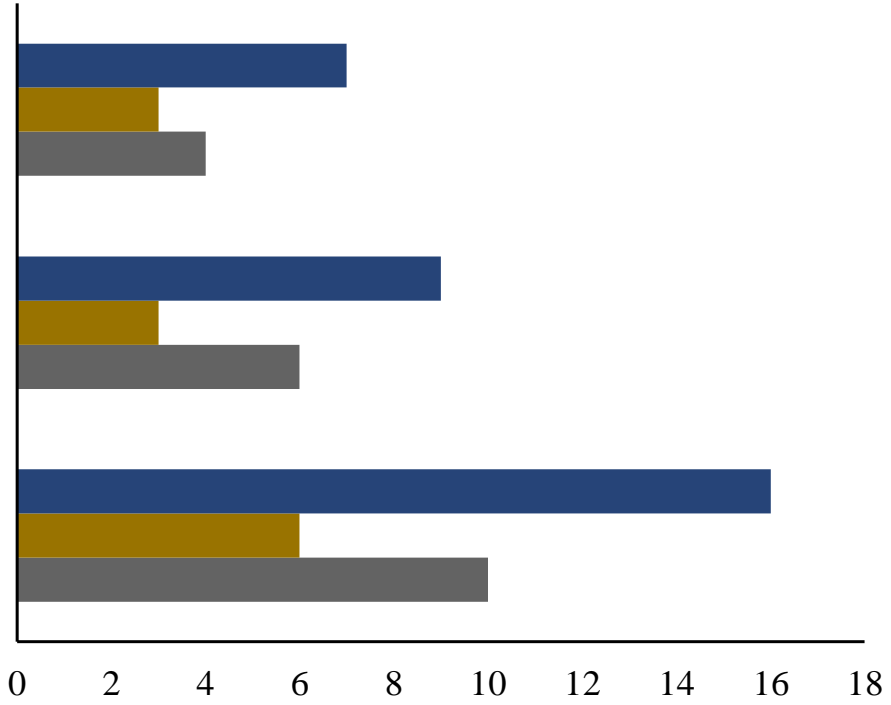

- Total Instalação do sistema operacional $\quad$ Montagem de computador

Fonte: Dados da pesquisa.

Quando questionados sobre o que deveria ser feito para melhorar o curso, 8 (oito) responderam à pergunta, 6 (seis) responderam que o curso deveria ter um tempo de durabilidade maior, 2 (dois) responderam ofertar material didático, apostila, conforme Gráfico 12.

Gráfico 12. Questionário sobre o que deveria ser feito para melhorar o minicurso de montador de computador oferecido no IFPA Campus Breves durante a I Escola de Férias.

Os participantes da comunidade externa responderam

Os participantes da Instituição de Ensino responderam

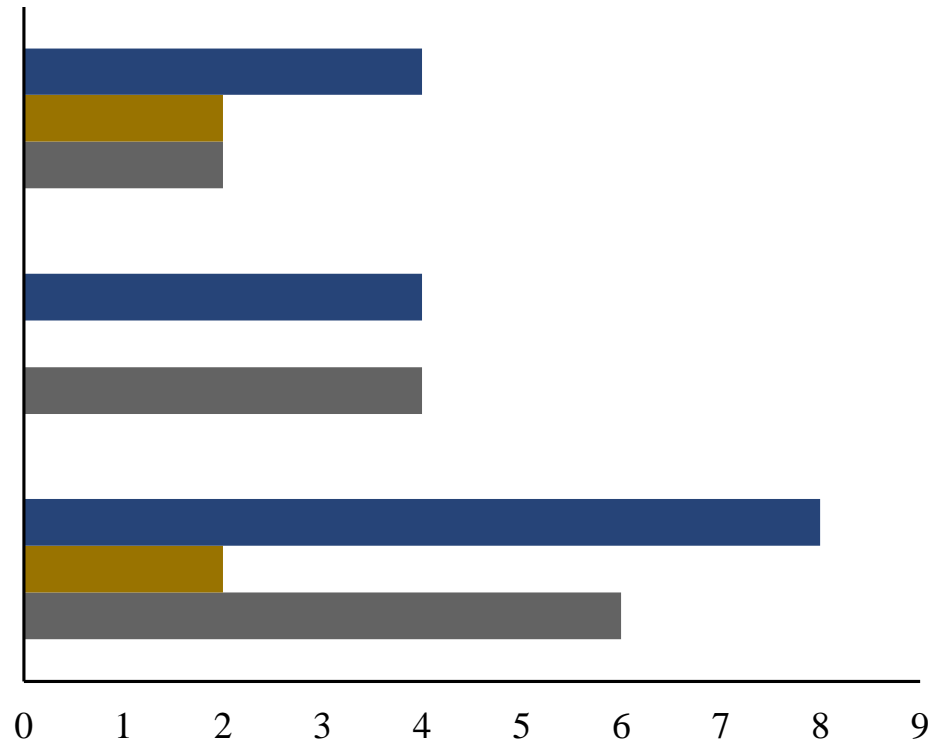

- Total $\quad$ Ofertar materiais didáticos $\quad$ Ofertar mais tempo de curso

Fonte: Dados da pesquisa.

O destaque deste resultado nos $75 \%$ no qual responderam que o curso deveria ter um tempo maior de duração. Esta informação sinaliza que o minicurso de montagem de computador, deve ampliar a carga horária para melhor atender esse 
público. Os outros $25 \%$, apontaram a necessidade de material de apoio, apostilas para facilitar o processo de aprendizagem. A relação do tempo e materiais didáticos são fatos relevantes para $100 \%$ dos que responderam essa pergunta para facilitar no processo ensino e aprendizagem. Neste sentido o minicurso deverá ser ofertado na modalidade de curso com carga horária superior a 20 horas.

Em relação aos pontos relevantes que o curso proporcionou para a formação, 12 (doze), responderam a pergunta. Desses 12 (doze), 10 (dez) responderam que conhecimento na área de montagem de computador é relevante. Do total de 10 (dez) participantes, 6 (seis) são alunos da Instituição e 4 (quatro) são da comunidade externa, conforme pode ser observado no Gráfico 13. Esses dados mostram que o ponto relevante que o curso proporcionou a eles foi mais conhecimentos, na área em questão.

Gráfico 13. Questionário sobre os pontos relevantes do minicurso de montador de computador oferecido no IFPA Campus Breves durante a I Escola de Férias

Os participantes da comunidade externa responderam

Os participantes da Instituição de Ensino responderam

Cite um ponto relevante que o curso proporcionou para sua formação.

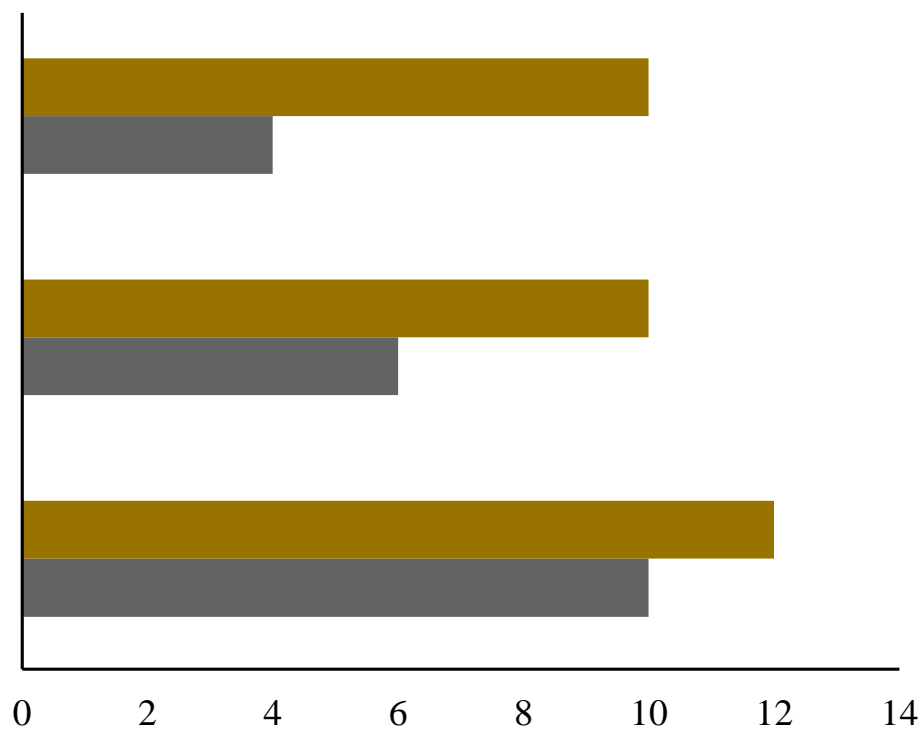

- Total $\quad$ Conhecimento na área

Fonte: Dados da pesquisa.

Quando foram questionados sobre a sugestão para contribuir com o curso para um melhor aproveitamento na aprendizagem, 12 (doze) responderam a pergunta, destes total, 5 (cinco) responderam ampliar o tempo de curso, percentual de 41,67\%, 3 (três) desses, são alunos da Instituição e 2 (dois) são da comunidade externa (Gráfico 14). Outros 2 (dois), sugeriram a ampliação do tempo do curso e quantidade de material didático (computadores). Outras 2 (duas) pessoas sugeriram, diversidade de material didático (notebook). Na sugestão de 2 pessoas, precisa de práticas individuais e 1 pessoas sugeriu que o minicurso proporcionasse material didático em formato de apostila. Essas sugestões são válidas para melhorar o processo de ensino e aprendizagem, principalmente em relação ao tempo que o minicurso proporciona. 
Gráfico 14. Questionário sobre sugestão do participante para o melhor aproveitamento no minicurso de montagem de computador oferecido no IFPA Campus Breves durante a I Escola de.

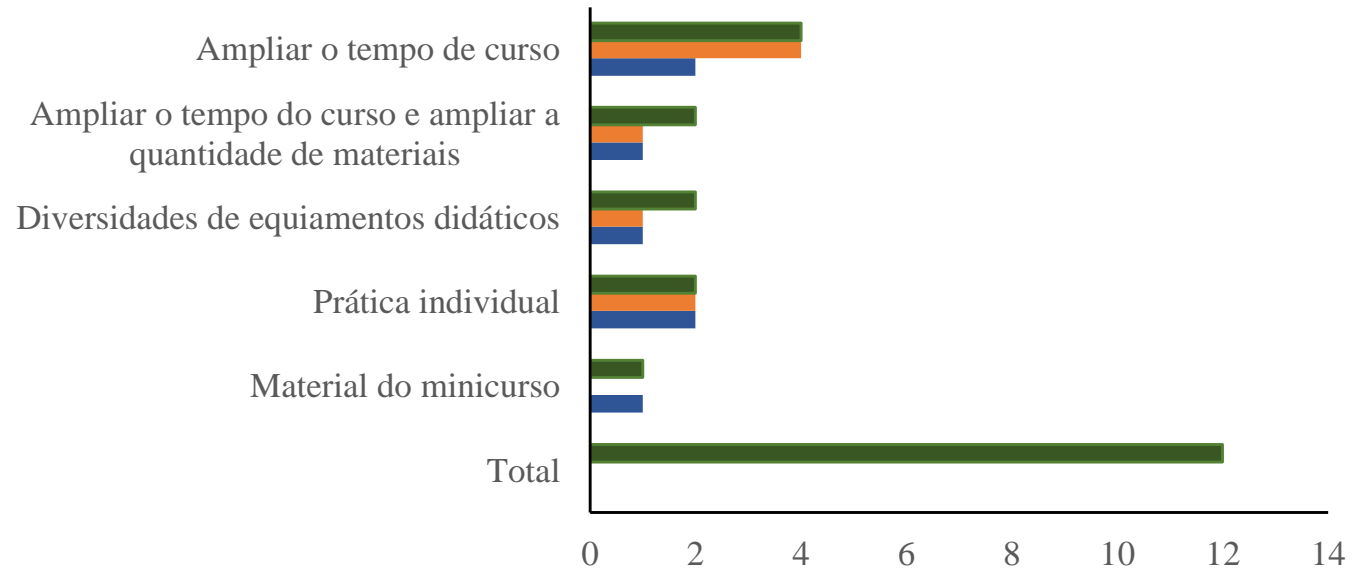

Qual sua sugestão para que você tenha melhor aproveitamento do curso de montador?

• Os participantes da Instituição de ensino responderam

- Os participantes da comunidade externa responderam

Fonte: Dados da pesquisa.

Quando questionados a respeito se já cursaram ou se estão cursando outra área de conhecimento, 18 (dezoito) responderam à pergunta, deste total, 12 (doze) responderam não e 6 (seis) responderam sim, conforme Gráfico 15.

Gráfico 15. Questionário se o participante tem e ou está cursando outra área de conhecimento do minicurso de montagem de computador oferecido no IFPA Campus Breves durante a I Escola de Férias.

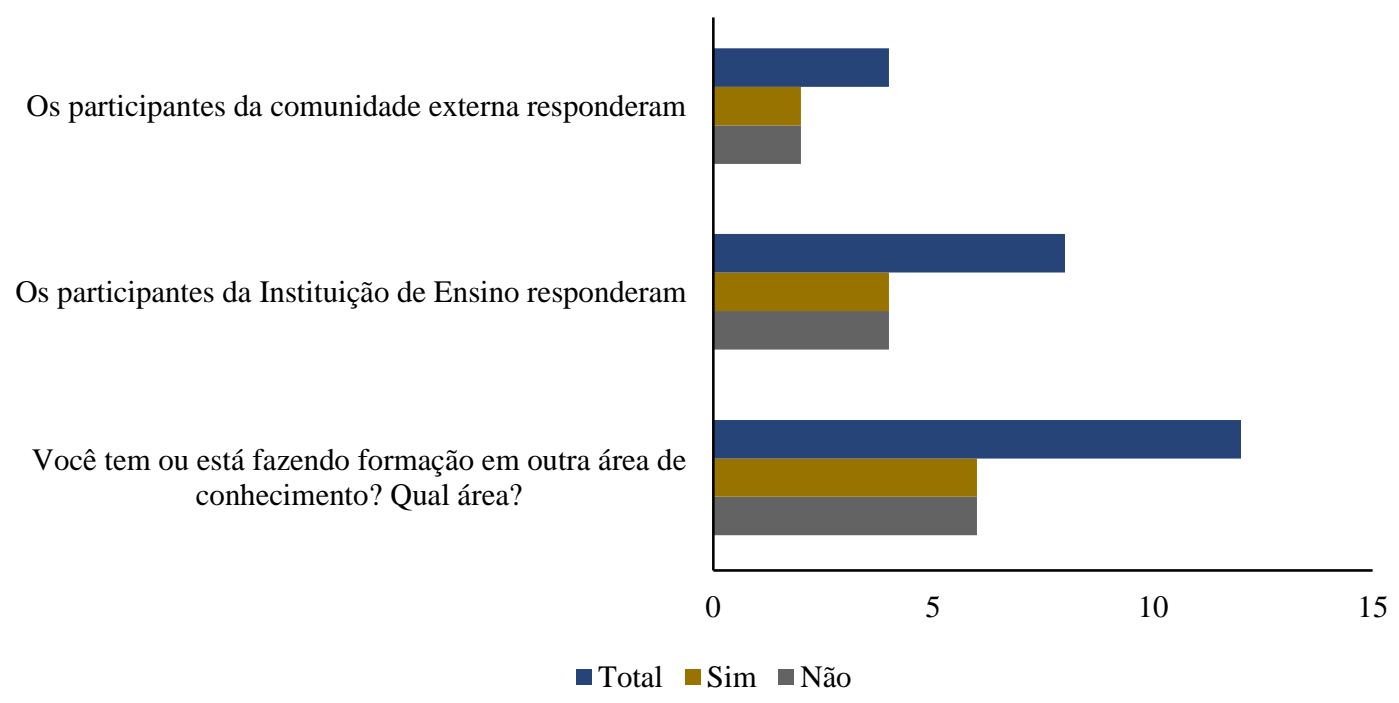

Fonte: Dados da pesquisa.

Destes 12 (doze) que responderam não à pergunta, 9 (nove) são da instituição de ensino, 3 são da comunidade externa (Gráfico 15). Os outros 6 (seis) participantes, 4 (quatro) são da comunidade externa e 2 (dois) são alunos da instituição de ensino. Os 9 (nove) alunos da instituição são alunos de informática, portanto, já é previsível uma afinidade na área. Em relação aos 3 (três) que são da comunidade externa, estes, podem, a partir das informações do minicurso, ingressarem na área de informática. A importância dessa pergunta para o conjunto do questionário é compreender quem é o público que o minicurso 
atendeu, qual o nível de escolaridade e grau de compreensão esse público teve do minicurso. Assim, é possível ter uma dimensão que o minicurso pode atingir e nas próximas versões apresentar alterações significativa na forma de atender esse público.

Dessa forma, o minicurso possibilitará aos participantes não apenas adquirir novos conhecimentos teóricos e práticos, mas também estabelecer vínculo entre a comunidade externa e a instituição de ensino através dos servidores que já se encontram inseridos na área de trabalho. Ressalta-se que conforme Hashimoto e Fonseca Júnior (2018), é importante que as instituições de ensino, principalmente dos cursos técnicos, promovam uma formação empreendedora aos estudantes que e, paralelamente, incentive os atuais empreendedores que não têm educação formal, a buscarem nas instituições de ensino, o aprendizado que servirá de guia para a realidade prática.

Este minicurso foi um projeto desenvolvido na "I Escola de Férias do IFPA", que realizou outras atividades de extensão. Os idealizadores das atividades irão desenvolver, de forma conjunta, novas ações de extensão, as quais deverão englobar as mais variadas áreas de informática e, se possível, promover a interdisciplinaridade entre áreas em um único projeto, a fim de mostrar aos seus participantes a notável indissociabilidade entre ensino-pesquisa-extensão.

\section{Considerações Finais}

A 'I Escola de Férias do IFPA - Campus Breves foi bem recebida pelos alunos e visou complementar o ensino de informática na educação através de atividades teóricas/práticas. Conforme os dados apresentados, percebe-se que o minicurso contribuiu para a formação de conceitos sobre a montagem de computadores, relacionados com o cotidiano dos alunos, e também durante o minicurso observou-se o empenho dos alunos e como essa metodologia foi atraente e eficiente para tornar o ensino mais agradável, uma vez que se aplicou a teoria e prática.

Em relação aos dados levantados sobre os 21 inscritos do minicurso de montador e reparador 90,47\% dos inscritos concluíram o curso, 9,53\% não iniciaram o curso, isso indica que o curso teve uma boa aceitação entre os participantes de forma geral. Essas informações recebeu um percentual indicador importante quando a questão levantada foi de quantos trabalham ou pretendiam trabalhar nessa área, a aceitação foi de 83,33\% e 16,67\% não se mostraram interessados.

De acordo como tempo de duração do minicurso observou-se que $75 \%$ dos entrevistados responderam que o tempo de duração do minicurso prejudicou no processo de aprendizagem, havendo a necessidade de um maior tempo para viabilizar o processo de ensino e aprendizagem. No entanto, o percentual de 52,94\% demonstra que o minicurso pode ser utilizado como um instrumento inovador e avaliativo fundamental em processos seletivos, capaz de orientar e direcionar os candidatos para a uma determinada área de conhecimento. Neste sentido, o minicurso pode ser utilizado como um instrumento inovador e avaliativo fundamental no processo seletivo para direcionar os candidatos para determinados cursos.

A realização dessa iniciativa possibilitou dimensionar a importância da extensão em vários âmbitos: na instituição, no curso de informática, na comunidade externa e na vida acadêmica e pessoal dos estudantes. Para as futuras edições, aspectos como divulgação, apoio, patrocínio e palestrantes podem ser potencializados, almejando, assim, a consolidação do evento no calendário institucional do Campus, e fomentando a oferta de atividades extracurriculares aos alunos e à comunidade externa, que se caracterizam pela indissociabilidade entre ensino-pesquisa-extensão.

Espera-se que os resultados contribuam para melhoria das práticas de ensino e extensão, que possa auxiliar e incentivar, especialmente no que tange a compreensão por parte dos professores das visões de natureza dos estudantes no sentido de permitir-lhes uma melhor aproximação com a prática profissional. Porém, torna-se necessário mais trabalhos neste viés para que se entenda de maneira mais sólida tais contribuições visando auxiliar no aprendizado aliando a teoria com a prática. 


\section{Referências}

Antunes, R. (2000). Adeus ao trabalho? Ensaio sobre as Metamorfoses e a centralidade do mundo do trabalho. ( $7^{\mathrm{a}}$ ed.,): Cortez.

Benakouche, T. (1999). Tecnologia é sociedade: contra a noção de impacto tecnológico. Caderno de Pesquisa, (17).1-20

Dooley, L. M. (2002). Case Study Research and Theory Building. Advances in Developing Human Resources, 4, (3), 335-354. https://www.researchgate.net/publication/255051693_Case_Study_Research_and_Theory_Building.

Gamboa, S. S. (2007). Pesquisa Educacional: quantidade qualidade: Cortez.

Gil, A. C. (2002). Como elaborar projetos de pesquisa. (4 ${ }^{\mathrm{a}}$ Ed.): Atlas.

Gil, A. C. (1999). Métodos e técnicas de pesquisa social: Atlas.

Gondin, S. M. G. (2002). Perfil profissional e mercado de trabalho: relação com a formação acadêmica pela perspectiva de estudantes universitários. Estudos de Psicologia, 7 (2) 299-309 https://www.scielo.br/scielo.php?pid=s1413-294x2002000200011\&script=sci_abstract\&tlng=pt.

Hennington, E. A. (2005). Acolhimento como prática interdisciplinar num programa de extensão universitária. Caderno de Saúde Pública, 21 (1) 256-265. https://www.scielo.br/scielo.php?pid=S0102-311X2005000100028\&script=sci_abstract\&tlng=pt

Koche, J. C. (2011). Fundamentos de metodologia científica. Petrópolis: Vozes. http://www.brunovivas.com/wpcontent/uploads/sites/10/2018/07/K\%C3\%B6che-Jos\%C3\%A9-Carlos0D0AFundamentos-de-metodologia-cient\%C3\%ADfica-_-teoriada0D0Aci\%C3\%AAncia-e-inicia\%C3\%A7\% C3\%A3o-\%C3\%A0pesquisa.pdfhttps://repositorio.ufsm.br/bitstream/handle/1/15824/Lic_Computacao_Metodologia-Pesquisa-Cientifica.pdf?sequence=1 .

Hashimoto, M., \& Fonseca Júnior, R. S. da (2018). A Importância do Ensino Empreendedor na Formação de Nível Técnico. Revista de Negócios, $10.7867 / 1980-4431.2018 v 23 n 3 p 7-18$

Lacerda, M. (2012). Informática como Disciplina Obrigatória na Educação Básica, Revista Texto Livre. In X Encontro Virtual de Documentação em Software Livre e VI Congresso Internacional de Linguagem e Tecnologia Online, 6(1), 2012. Anais... http://www.periodicos.letras.ufmg.br/index.php/anais_linguagem_tecnologia/article/view/1882.

Lakatos, E. M., \& Marconi, M. de A. (2009). Fundamentos de metodologia científica. (6 ${ }^{\mathrm{a}}$ ed.) 7. reimpr.: Atlas.

Lang, A. G. (2007). Ambientes virtuais complementando o espaço formal de aprendizagem. 95f. (Dissertação de Mestrado em Educação nas Ciências da Universidade Regional do Noroeste do Sula http://bibliodigital.unijui.edu.br:8080/xmlui/bitstream/handle/123456789/379/Adriano\%20Lang.pdf?sequence=1.

Luckesi, C. C. (2005). Avaliação da Aprendizagem Escolar. (17 ed.) : Cortez.

Moreira, A. R., Santos, A. E. dos., Cardoso, B. P O., Fonsaca, B. de L., Rosa, E. G., Ferreira, E. C. B., \& Tozi, G. (2020). A educação profissional e sua importância no mercado de trabalho. Inova + Cadernos da Graduação da Faculdade da Indústria, 2, (1) 54-94. http://app.fiepr.org.br/revistacientifica/index.php/inovamais/article/view/467.

Minarelli, J. A. (1995). Empregabilidade: o caminho das pedras: Gente.

Paz, J. R. L. da S., M. V. P. dos., Silva, W. P., Moreira, A. L. da C., \& Santana, C. C. A (2014). A importância da organização de eventos acadêmicos na formação do biólogo: a iniciativa do BioVertentes. Revista em $\quad$ Extensão (Online), 13 (1) 51-60. www.seer.ufu.br/index.php/revextensao/article/viewFile/23293/14680.

Pereira, A. K., Koshino, M. F., Ferreira, T. R., \& Rocha, R. A da. (2011). A importância das atividades extracurriculares universitárias para o alcance dos objetivos profissionais dos alunos de administração da Universidade Federal de Santa Catarina. Revista Gestão Universitária na América Latina, Florianópolis, 4 (3), 163-194. https://periodicos.ufsc.br/index.php/gual/article/view/1983-4535.2011v4nespp163.

Peres, C. M. (2006). Atividades extracurriculares: Representações e vivencias durante a formação médica. 151 f. (Dissertação de Mestrado, Programa de PósGraduação em Psicologia, Universidade de São Paulo).

Santos, M. (2001). Por uma outra globalização: do pensamento único à consciência universal. (6ed.): Record.

Souza, D. F. P (2010). Laboratório de Informática: Ferramenta de Aprendizagem nos Anos Iniciais. 37 f. (Trabalho de Conclusão de Curso de Licenciatura em Pedagogia da Faculdade de Educação da Universidade Federal do Rio Grande do Sul) http://www.lume.ufrgs.br/bitstream/handle/10183/35815/000815457.pdf?sequence=1.

Winterhalter, D. F., \& Nogueira V. (2012). As contribuições do estágio extracurricular para formação docente. Simpósio de Ensino, Pesquisa e Extensão, 14, 2012. Anais . Santa Maria: Unifra, 2012. 